\title{
ICARE Model Integrated with Science Magic to Improvement of Students' Cognitive Competence In Heat and Temperature Subject
}

\author{
Yoana Nurul Asri \\ Physics Program, School of Postgraduate Studies \\ Indonesia University of Education, Setiabudhi St, No.229 \\ Bandung, West Java, 40154
}

Email: ynurulasri@gmail.com

\author{
Dadi Rusdiana \\ Physics Education Department \\ Indonesia University of Education, Setiabudhi St, No.229 \\ Bandung, West Java, 40154
}

\author{
Selly Feranie \\ Physics Education Department \\ Indonesia University of Education, Setiabudhi St, No.229 \\ Bandung, West Java, 40154
}

\begin{abstract}
The aim of this study is to determine the increasing of student's cognitive competence students impact to implementation of ICARE model integrated with science magic and ICARE model without science magic in heat and temperature subject. The ICARE model involves some cycles, namely: introduction, connection, application, reflection, and extension. The subjects of the research consist of 76 students at $10^{\text {th }}$ grade of senior high school existing in Bandung city with two classes in control and experiment group. Science Magic aims at increasing students' attention and interest towards physics. This study was done in three phase: 1) Preparation stage includes literature study, field study and instrument and lesson plan composition; 2) Implementation stage includes giving a treatment to the subjects of the research; and 3) Final stage includes analyzing and discussing data. As a result of the research, it was found that implementation of ICARE integrated with science magic is better and more effective than ICARE without science magic in heat and temperature, proved by average score $\mathrm{N}$-gain of misconception are 0.36 and 0.54 .
\end{abstract}

Keywords-Cognitive Competence; ICARE Model; Science Magic

\section{INTRODUCTION}

Education is one of alternatives to prepare someone to be skillful and is able to compete in life in future time. We are in modern life now and of course we need intellectual resource; involving logical reasoning capacity, thinking systematic, critical, accurate, and creative thought, and capacity to communicate ideas especially in solving the problems. Those capacities should be developed by the learning process through affective, cognitive or psychomotor aspect.

Boring learning activities will block students' interest to physics, whether it is because of monotonous strategy, abstract or the teachers' behavior and make influence their learning process in cognitive competence. They learn Physics because of the demand of school curriculum rather than its needs.
Additionally, Physics learning seems useless since the application of non-contextual learning.

Based on the observation conducted, it is found that Physics learning activity of the first grade students of a senior high school in Bandung is not effective yet. The learning process is teacher-centered, and the teacher does not attempt to dig students' basic competence in attempt to involve them in learning process. As a result, the students get difficulties in understanding the subject matters being taught and the learning outcome could not be achieved. It could be proved by the Physics average scores obtained by students in year $2005 / 2016$ which is under standard value.

Problems solving are innovative learning that can build interest student in Physics and increase their cognitive competence is needed. In this case, the teaching and learning process by applying ICARE model, namely; introduction, connection, application, reflection, and extension require to conduct. Based on related research report conducted this learning model was designed to facilitate online learning module development effectivelyand useful components of an online course [1]. In 2006, United Stated Agency International Development (USAID) of Indonesia applied ICARE model offline in a workshop on the teachers and learning process at school through Decentralized Basic Education (DBE) program.

Instead of improving students' cognitive capacity, the model need also build positive attitude towards Physics so that they are interested in learning it.Attitude affects someone' view towards an object [6] and it will influenced by science magic. Some concepts could be started by showing some science phenomena through magic science before moving to the main activity. In each activity, science magic practice could be used to develop learning activities and thus learning strategies should be adopted to increase the learning outcome. 


\section{RESEARCH METHOD}

In this research used pre-test post-test control group design. One class as experiment group by ICARE model integrated with science magic and other as control group by ICARE model without science magic. Populations in this study were all students of tenth grade in one of senior high school in Bandung city. The samples in this study were selected using purposive sampling technique, 76 students at two groups.

At the phase teacher give pretest and continue with ICARE model include: introduction, in which teachers teach the subject matters by explaining learning objectives, learning outcome, apperception, and motivation, the connection, in which teachers provide some information in the form of facts, concepts, and processes in day to day life. The application, teachers make students to apply their knowledge and skills. The reflection, in which teachers review students' comprehension, and the extension, students enforce and extend learning. In experiment group with science magic insert at second which connection done for grow up they interest in physics. After learning for two weeks, posttest given.

\section{RESULTS AND DISCUSSION}

Table 1 presents percentage of students' pretest-posttest result and $\mathrm{N}$-gain. Table 1 shows the mean of pre, post and $\mathrm{N}$ gain data of students' cognitive competence test. As can be seen from Table 1 value for posttest is higher than pretest at experiment group witch ICARE model integrated with science magic, $\mathrm{N}$-gain also.

TABLE I. THE MEAN RESULTS FROM THE PRE AND POST DATA OF STUDENTS COGNITIVE COMPETENCE TEST

\begin{tabular}{|c|c|c|}
\hline \multirow{2}{*}{ Aspect } & \multicolumn{2}{|c|}{ Mean } \\
\cline { 2 - 3 } & Control group & Experiment group \\
\hline Pretest & 0.29 & 0.28 \\
\hline Posttest & 0.55 & 0.67 \\
\hline N-gain & 0.36 & 0.54 \\
\hline
\end{tabular}

As seen from Table 2, at experiment group always gets higher $\mathrm{N}$-gain than control group at cognitive competence category. These was means that ICARE model integrated with science magic facilitate students to actively participate in constructing knowledge at connection phase when science magic insert. In this process the students are faced with a situation where they interest and encourage students during learning physics. The revised Bloom Taxonomy which was developed [5] contains two dimension of knowledge, namely, cognitive process dimension and knowledge dimension. The interrelation between the two dimensions further called as Anderson Taxonomy.

TABLE II. .N-GAIN IS A COGNITIVE COMPETENCE CATEGORYOF STUDENTS

\begin{tabular}{ccc}
\hline $\begin{array}{c}\text { Cognitive } \\
\text { Competence } \\
\text { Category }\end{array}$ & \multicolumn{2}{c}{ N-gain } \\
\cline { 2 - 3 } & Control Group & Experiment Group \\
\hline $\mathrm{C} 1$ & 0.37 & 0.57 \\
\hline $\mathrm{C} 2$ & 0.36 & 0.52 \\
\hline $\mathrm{C} 3$ & 0.44 & 0.51 \\
\hline $\mathrm{C} 4$ & 0.22 & 0.46 \\
\hline
\end{tabular}

In spite of, ICARE model provides teachers opportunities to change students' learning experience through the emphasis on each its cycle [2]. In the connection phase, teachers can deepen students' concepts effectively. These concepts can be integrated with Science Magic activity so that the learning process could be more contextual. In addition, through the application of Science Magic in the extension phase, students will understand the concepts more based on some phenomena occurred frequently in their surroundings. The last, the application of ICARE model provides teachers some chances to create specific module in accordance with some competences which will be drilled [3].

Many researchers represent that in teaching science and the learning process, science magic activity is very effective to apply because it can stimulate students' interest and encourage students [4] to participate actively in some learning instruction.

Science magic activity encourages students to maintain their motivation and interest during the learning activities so that learning objectives could be achieved easily. The appearance of science magic showed in Fig 1.

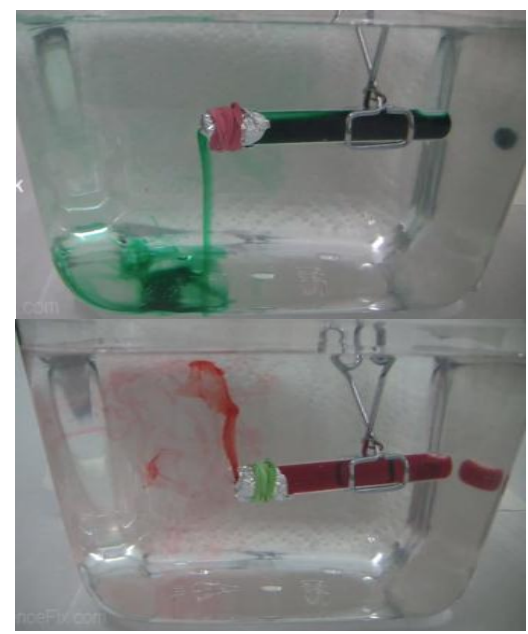

Fig. 1. Science magic appearance about convection

By integrating science magic, it is hoped that students will be facilitated to result in cognitive conflicts and enforce students' motivation, attention, and interest during the learning process since Physics is taught through fun activities by applying ICARE model integrated with Science Magic phenomenon. Thus, it is hoped that students' attitude towards Physics could be positive as well as their cognitive competence could be improved.

\section{CONCLUSION}

Research has shown that implementation ICARE model integrated with science magic can improve students cognitive competence better than without science magic. Students' motivation, attention, and interest during the learning process since Physics is taught through fun activities by applying ICARE model integrated with Science Magic phenomenon's which improve they ability to understand concept very well. 


\section{References}

[1] Hoffman, Bob., \& Ritchie, Donn. C. Teaching and Learning Online: Tools, Templates, and Training. Society for Information Technology \& Teacher Education International Conference. 1998. (P 113-117). Washington: ERIC

[2] Byrum, David. Instructional Module Development Using the ICARE Model with Novice Designers. Educational Technology. 2013.

[3] Ress, Dianne. The ICARE Model and Course Design Instructional Design Fusions Walgito, Ben. 1978. Social Psychology (An Introduction). Yogyakarta: Andi Bell, L., \& Bull, G. L, Digital Video and Teaching, 2011. 10, 2010, pp.1-6.

[4] Arnold, J. C., Kremer, K., \& Mayer, J. Understanding Students' Experiments-What kind of support do they need in inquiry tasks? International Journal of Science Education. Advance online publication doi: 10.1080 / 09500693.2014.930209Jasmy, M., Rahman, A., Arif, M.,
Ismail, H., \& Nasir, M. Development and Evaluation of the Effectiveness of Computer-Assisted Physics Instruction, 2014. 7(13), pp $14-22$.

[5] Anderson, I.W. \& Krathwohl, D.R. Framework for Learning, Teaching and Assessment Revised Bloom's Taxonomy of Educational. Yogyakarta: Library LearningTenenbaum, G. (2001). Constructivist pedagogy in conventional on- campus and distance learning practice : an exploratory investigation, 2010. 11, pp. 87-111

[6] Lena, Assaraf, Orit. Attitude Toward Science Learning Among 10th Grade Students: A Qualitative Look. International Journal of Science Education. Vol 33, No.9Tsai, C., The interpretation construction design model for teaching science and its applications to Internet-based instruction in Taiwan, 2011. 21, 2001, pp.401-415 